\title{
O DIREITO E A PROPRIEDADE INTELECTUAL: CONSTITUCIONALIZAÇÃO, CAMPO DE ATUAÇÃO E RESPONSABILIDADE A VIOLAÇÃO DO DIREITO.
}

\section{LAW AND INTELLECTUAL PROPERTY: CONSTITUTIONALIZATION, FIELD OF ACTION AND LIABILITY FOR LAW.}

\author{
*GOMES, Rita de Cassia Medeiros ${ }^{1}$ \\ https://orcid.org/0000-0001-8362-019X \\ http://lattes.cnpq.br/0264016279066537
}

RECEIVED /RECEBIDO 18/12/2019 FEV 2020

APPROVED/APROVADO 20/12/2019 FEV 2020

PUBLISHED /PUBLICADO 13/01/2020 FEV 2020

Editor Responsável: Carla Caldas

Método de Avaliação: Double Blind Review

E-ISSN: 2316-8080

Prefixo do DOI: 10.16928

RESUMO

O presente trabalho faz parte de um capítulo do Trabalho de Conclusão de Curso de Direito, intitulado como: A Propriedade Intelectual e as diferentes formas de proteção: perspectivas de amparo legal e de atuação, tendo por finalidade estudar o Instituto Propriedade Intelectual, seu sistema de proteção, sua influência nos diversos campos do Direito e a relação deste com a Propriedade Intelectual. Ainda, a sua contribuição para a sociedade, sua relevante função social, o incentivo a pesquisa, inovação e, criação, tendo à indústria, a economia, a universidade e a criação humana como pontes para consolidar o Instituto, com destaque para a temática acima objetivando relacionar os direitos de Propriedade Intelectual nos âmbitos do Direito em relação à Constituição Federal, a responsabilidade e violação dos direitos: Civil, Penal e Administrativa ,bem como a atuação de outros campos do Direito em relação ao Instituto Propriedade Intelectual, através da revisão literária em diversas fontes bibliográficas. Em relação à proposta de pesquisa, tem-se como objeto de estudo o "Instituto Propriedade Intelectual", e legalmente como está amparada, através de pesquisas em fontes diversas e atualizada. Tendo assim, a seguinte problemática: Quais contribuições importantes a Propriedade Intelectual pode proporcionar, tanto para a sociedade, como para o campo científico e de atuação? A metodologia de pesquisa está fundamentada na pesquisa bibliográfica e o método utilizado é a revisão literária narrativa, sendo está uma pesquisa qualitativa e descritiva. Foi possível perceber grande embate doutrinário e jurisprudencial quanto ao objeto pesquisado e o sistema de sua proteção. No entanto, também foi possível detectar

\footnotetext{
${ }^{1}$ Mestre em Educação pela Pontifício Universidade Católica de Campinas-PUCCampinas/SP, na linha de pesquisa: Ensino Superior- Universidade, Formação de Professores.

Especialista em Planejamento e Gestão em Organização da Educação Escolar pela UNESP de Araraquara/SP
} 
a relevante importância desse instituto para o avanço: social, econômico, cultural e se assim for possível manifestar, a percepção de um estudo e conhecimento híbrido que perpassa por vários campos de atuação e domínio, além do Direito.

Palavras-Chave: Propriedade Intelectual. Criação. Proteção. Direito. Fução Social.

\begin{abstract}
The purpose of this Course Completion Work is to study the Copyright Law Institute, its protection system, its influence in the various fields of Law and its relation with Copyright Law. Also, its contribution to society, its excellent social function, the incentive to research, and creation, taking industry, economy, university and human creation as bridges to consolidate the Institute. Regarding the research proposal, the object of study is the "Institute of Copyright", with the objective of investigating the important contributions that the Copyright Law can provide, both for society and for the scientific, social areas, economic, moral, professional and legally as it is supported, through research in various sources and up-to-date in the field. Having thus, following the problematic: What important contributions can Copyright provide, both for society, and for the scientific field, of performance and legally as supported? The research methodology is based on bibliographic research and the method used is the narrative of literary revision, this being a qualitative and descriptive research that had as execution schedule the period from February to November of 2018. It was possible to perceive great doctrinal principles and case law. the object sought and the system of its protection. However, it was also possible to detect the excellent importance of this institute for the social, economic, cultural and if it is possible to reveal, the perception of a study and hybrid knowledge that runs through some fields of action and domain beyond the right.
\end{abstract}

Keywords: Intellectual Property. Creation. Protection. Right. Social Role.

\title{
RESUMEN
}

El propósito de este trabajo de finalización del curso es estudiar el Copyright Law Institute, su sistema de protección, su influencia en los diversos campos del derecho y su relación con el derecho de autor. Además, su contribución a la sociedad, su excelente función social, el incentivo para la investigación y creación, tomando la industria, la economía, la universidad y la creación humana como puentes para consolidar el Instituto. Con respecto a la propuesta de investigación, el objeto de estudio es el "Instituto de Derechos de Autor", con el objetivo de investigar las importantes contribuciones que la Ley de Derechos de Autor puede proporcionar, tanto para la sociedad como para las áreas científicas, sociales, económicas, morales, profesionales y legales. tal como está respaldado, a través de investigaciones en diversas fuentes y actualizadas en el campo. Teniendo así, siguiendo la problemática: ¿Qué contribuciones importantes pueden tener los derechos de autor, tanto para la sociedad como para el campo científico, de desempeño y legalmente como apoyados? La metodología de investigación se basa en la investigación bibliográfica y el método utilizado es la narración de la revisión literaria, siendo esta una investigación cualitativa y descriptiva que tuvo como cronograma de 
ejecución el período de febrero a noviembre de 2018. Fue posible percibir grandes principios y casos doctrinales. ley. El objeto buscado y el sistema de su protección. Sin embargo, también fue posible detectar la excelente importancia de este instituto para lo social, económico, cultural y, si es posible revelar, la percepción de un estudio y conocimiento híbrido que atraviesa algunos campos de acción y dominio más allá del derecho.

Palabras Clave: Propiedad Intelectual. Creación Protección. Derecho. Función Social.

\section{O Direito e a Propriedade Intelectual: Constitucionalização, campo de atuação e responsabilidade a violação do direito.}

\section{1-Introdução.}

O tema selecionado para a pesquisa do Trabalho de Conclusão de Curso, desperta o interesse, por ser uma área que abrange formas variadas à proteção da criação humana, de seus atos criativos e intelectuais afins, geralmente com a finalidade de produzir ideias e as materializar, tendo impacto tanto na economia como na tecnologia, com cunho de função social, comercial e econômica, além de estar presente no nosso dia-a-dia .

Ainda justifica-se que o trabalho proposto: O Direito e a Propriedade Intelectual: Constitucionalização, campo de atuação e responsabilidade a violação do direito, merece atenção porque é um assunto de interesse coletivo, visto que a temática oferece muitas informações relevantes que podem ajudar a entender todo um sistema de proteção da criação das ideias em um contexto social capitalista e competitivo, cujo autor da criação além do direito de ser reconhecido intelectualmente por sua obra, também terá o direito de reivindicar os proventos econômicos de sua criação e demais direitos que lhe forem pertinentes. E é neste contexto que entra o Sistema de Propriedade Intelectual para garantir a proteção legal aos criadores sobre suas criações.

Assim para promover a pesquisa, procurou-se a resposta a partir do seguinte questionamento: Como a Propriedade Intelectual está amparada legalmente e qual suporte. jurídico se apoia quanto a violação de seus direitos. A pesquisa é com foco na 
metodologia bibliográfica, com suporte no método da Revisão de Literatura Narrativa, sendo está uma pesquisa qualitativa e descritiva.

Entende-se como Revisão Literária, segundo o manual de pesquisa da Biblioteca Dante Moreira Leite do Instituto de Psicologia da Universidade de São Paulo-USP (2015), sendo processo que tem como finalidade, buscar, analisar e realizar descrição de um corpo do conhecimento para encontrar resposta a uma pergunta específica, em que, a Literatura cobre todo material relevante que é escrito sobre um tema: livros, artigos de periódicos, artigos de jornais, registros históricos, relatórios governamentais, teses e dissertações e outros tipos.

Sendo que os tipos de Revisão da Literatura se destacam em: narrativa, sistemática e integrativa. No caso desta pesquisa, será a Revisão da Literatura Narrativa, visando não utilizar critérios explícitos e sistemáticos na busca e análise crítica da literatura, sendo adequada para a fundamentação teórica de artigos, dissertação, teses, trabalhos de conclusão de cursos.

E como Metodologia de Pesquisa Bibliográfica, pesquisa desenvolvida a partir de material já existente, constituído principalmente de livros e artigos científicos.

\section{2- Concepção de Direito e sua relação com a Propriedade Intelectual.}

Procura-se neste momento, apresentar a importância do amparo legal à proteção do Sistema de Propriedade Intelectual. Para isso fica necessário, como fundamento teórico, discorrer sobre a concepção de Direito no transcorrer dos tempos; a posição do Direito frente à Estrutura Normativa do Ordenamento Jurídico Brasileiro na perspectiva da Constituição Federal de 1988 e sobre a responsabilidade quanto à violação dos direitos, em relação a Propriedade Intelectual.

A concepção de Direito também acompanha a evolução social, e o que mais se aproxima da ideia a ser desenvolvida neste trabalho, visando a Propriedade Intelectual é a de Direito como sistema de normas que regulam as relações humanas e a faculdade que defende os interesses pessoais, associada também a ideia de ramo dos estudos referentes às normas jurídicas. No entanto, ao pesquisar sobre foi possível perceber um paradigma de ambiguidades.

Segundo Gusmão, citado por Caminha (2018), o pensamento filosófico jurídico em torno da concepção de Direito mantém-se em duas correntes antagônicas: 
1-A dos que admitem uma concepção universal de Direito, em que se encontram os denominados Idealistas ou Neokantianos e Criticistas que defendem a ideia de que a experiência jurídica somente seria possível com o auxílio da definição a priori, justificada pela necessidade de se definir a concepção pela razão, desconsiderando a experiência.

2- A dos que entendem ser impossível estabelecer uma única concepção de Direito em que se encontram os Positivistas que defendem a ideia de que a concepção de Direito é formada através de generalizações dos dados obtidos por meio da experiência jurídica e que seria possível somente a posteriori, em que se estabelece um critério de Direito indispensável para selecionar o fenômeno jurídico dos demais fenômenos históricos.

Segundo Vecchio (2016):

(...) se a noção comum e vaga de Direito pode às vezes bastar para certos fins particulares, é, contudo insuficiente para os fins superiores do conhecimento. As manifestações vulgares da atividade jurídica são facilmente reconhecidas por todos, porém, frente aos problemas mais elevados e gerais, quando se trata de situar a ideia do Direito na ordem do saber, de determinar-lhe os elementos essenciais, de distingui-la de outros objetos e categorias afins, surgem dúvidas e dificuldades que a noção vulgar é importante para resolver. A solução de tais problemas requer uma investigação que não pode ser feita por nenhuma ciência jurídica stricto sensu, isto é, do Direito Positivo, porque cada uma destas ciências tem por objeto só uma parte da realidade jurídica, enquanto que a definição lógica deve abranger todos os sistemas jurídicos, inclusive o não positivo; isto é: indicar o limite de toda a possível experiência jurídica (p.05).

Dessa forma, pode-se entender que a termologia se aplica a realidades distintas, exigindo não somente uma única definição, mas tantas quantas necessárias para explicar a realidade a qual se adéqua, ou seja, objeto de estudo, tendo a construção do Direito fluente em diversos momentos históricos.

Vejam-se algumas concepções sobre, segundo alguns doutrinadores:

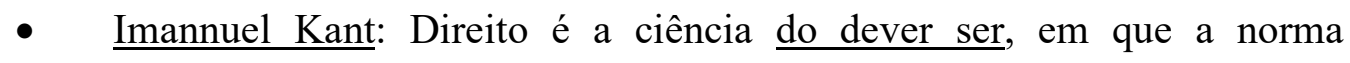
constituiria o imperativo categórico, compreendido como, conjunto de condições em que o arbítrio de um pode conciliar-se com o arbítrio do outro, segundo lei geral de liberdade, ou seja, funda-se a ideia de Direito na norma legislada, prescrita para regular o modo de agir das pessoas, com vigência, eficácia em lugar e tempo predeterminado, dirigindo-se a todos os membros da sociedade e que traz consigo implícito o sentido de dever. 
- $\quad$ Hans Kelsen: O Direito se constitui por normas coativas, com validade fundada em norma fundamental, ou seja, a lei para possuir eficácia e vigência válidas deve ter previsão do legislador originário que a estabeleceu na Constituição.

- $\quad$ Miguel Reale, crítico do normativismo kelseniano, em sua teoria da Tridimensionalidade do Direito- Direito para este, não é somente norma como Kelsen defendia, nem fato como os marxistas ou economistas do Direito pensam. Embora, Direito não seja produção econômica, mas envolve esta e nela interfere. Tampouco o Direito seja valor, como defendem os adeptos do Direito Natural. Defende Reale (1998) que sim, Direito é ao mesmo tempo: Fato, Valor e, Norma ou seja Direito é integração normativa dos fatos segundo valores, estando estes sempre presentes na substância do jurídico . Entende-se a partir dos pressupostos de Lima (2018) que, Fato é compreendido neste contexto como referência ao mundo da natureza e do ser, em que atua como determinantes dos acontecimentos históricos, que Valor é considerado como elemento que traduz o mundo ético ou da cultura, presentes a moral e aos costumes e que; Norma é entendida como a ciência do direito e normas de conduta desejável e estabelecida pelo e para o meio social. Assim, escreve o autor acima citado que Miguel Reale (1998) apresenta a concepção de Direito como concretização da ideia de justiça em uma visão de contexto da pluridiversidade, de seu dever-ser histórico, sendo a pessoa a fonte de todos os valores.

- $\quad$ Norberto Bobbio: O Direito, não é norma e sim um conjunto coordenado de normas, sendo que uma norma jurídica não se encontra isolada, mas articulada a outras normas com as quais forma um sistema normativo.

Ao discorrer sobre a ideia de concepção de Direito com relação à Propriedade Intelectual e o Sistema de Proteção à criação humana, pode-se perceber que, faz jus aos pressupostos do autor supracitado, em que: “Direito, entre outras concepções, pode ser visto como conjunto de regras e princípios que, em busca de proteger a paz social, visa a conceber a Justiça, concedendo a cada qual o que é seu" (p.09). No entanto, pode-se considerar também por outra perspectiva que o Direito há de ser considerado ao mesmo tempo: Fato, Valor e Norma e que, o Direito também deve considerar a ideia que é formado por um conjunto de normas articuladas umas às outras, mesmo que cada uma possua a sua especificidade, mas isoladamente, não tem ao mesmo tempo: eficácia (capacidade de modificação do mundo jurídico) e eficiência ( que produza resultado) . 
Veja-se também a importância das seguintes concepções para melhor entendimento dos campos de atuação do Direito em que a Propriedade Intelectual se apoia para se proteger juridicamente, em relação aos fundamentos da classificação do Direito Público e do Direito Privado, visto que o que pertence a um, não pertence ao outro, não havendo nada que seja público e privado simultaneamente, todos os fenômenos são enquadrados num ou em outro. As duas esferas: Pública e Privada se delimitam mutualmente, em que uma possui a sua limitação quando a outra começa assumindo valoração oposta um ao outro.

1-Direito Privado: O interesse é individual, em que o tipo de relação social predominante é as relações entre iguais, de coordenação. É uma igualdade formal, voltada para as relações econômicas (mercado). O tipo de regra vinculatória da conduta é o contrato. Logo, frisa-se que há proteção a interesses privados; princípios que o fundamentam como: autonomia da vontade; igualdade formal, conceito de legalidade relacionada ao de liberdade, em que o relacionado ao de liberdade tem afirmação no que é expressamente proibido, é permitido. Ainda regula entre os particulares, individuo, as suas relações, podendo dispor sobre seus próprios interesses, dentro de determinados limites- interesses disponíveis. Prevalecem as normas permissivas, embora existam princípios de ordem pública estes, não alteráveis por vontade das partes. Assim o Direito Privado, tem por finalidade principal a regulação dos interesses particulares, prevalecendo à igualdade das partes, não existindo subordinação de uma a outra.

Compreendem os ramos do Direito Privado: a- Direito Civil, é Direito que possui como objeto, os atos elementares da vida civil e que regula as relações entre particulares, inclusive as patrimoniais e pessoais, no que diz respeito: aos contratos, a propriedade, ao casamento, as sucessões, as obrigações, dentre outros; b- Direito Comercial ou Empresarial, é o Direito concernente às empresas e suas atividades, destacando-se do Direito Civil, pelas regras especificas aplicadas à área empresarial, cujo princípio básico é proteger e garantir a circulação e o crédito e; c- Direito Internacional Privado, é ramo do Direito que define os princípios, formula os critérios, estabelece as normas a que se deve obedecer, visando a melhor solução para os conflitos emergentes de relações jurídicas privados internacionais.

2-Direito Público: É Direito concernente às relações públicas jurídicas de natureza pública. O interesse envolvido é coletivo, em que predominam as relações entre desiguais, 
marcadas por relações de subordinação- comando e obediência - esfera política. Aqui o tipo vinculatório da conduta é a Lei: norma que obriga a todos submetidos ao poder soberano.

Compreendem os ramos do Direito Público: a- Direito Constitucional, é o Direito posto pelo povo sem à observância do governo, tendo como fundamento as normas básicas sem organização do Estado e da Sociedade. É, segundo Moraes (2014), juridicamente que a Constituição Federal deva ser compreendida como a lei fundamental e suprema de um Estado, que contém normas referentes à estruturação do Estado, à formação dos poderes públicos, forma de governo e aquisição do poder de governar; bDireito Administrativo, é Direito pertinente à atividade da administração pública como tal e, está relacionado com as normas sobre a organização do Estado no exercício de sua função administrativa/ executiva. Segundo, Justen (2005, p.05) são normas jurídicas de direito público que disciplinam as atividades administrativas à realização dos direitos fundamentais e a organização e o funcionamento das estruturas estatais e não estatais; cDireito Financeiro, é Direito que possui como objeto, os fatos financeiros, voltados para a receita e despesas do Estado; d- Direito Tributário, é Direito concernente aos tributos e ramo do Direito responsável por criar um conjunto de leis que regulamentam a arrecadação e fiscalização de tributos; e- Direito Penal, é Direito criminal, cujo objeto é o ilícito penal, sendo ramo do Direito que se dedica a estabelecer as infrações penais e suas respectivas sanções (penas e medidas de segurança); f- Direito Internacional Público- É Direito concernente às relações públicas internacionais, consistindo em um sistema jurídico autônomo, onde ordenam as relações entre Estados soberanos, ou seja, ramo do Direito que tem por finalidade regular as relações interestatais, bem como as relações das organizações internacionais e dos indivíduos, visando a universalidade; gDireito Processual- é ramo do Direito que estuda e trata dos assuntos referentes ao processo, ou seja, trata da sequência de atos destinados a um fim, o da jurisdição, enfim dentre outros ramos do Direito não citados neste momento. Cabe aqui ressaltar dentre os citados, com mais frequência, o Direito Empresarial; Direito Civil; Direito Constitucional Direito Internacional e Direito Administrativo, visando realizar um breve recorte para frisar o objeto de pesquisa: "O Instituto de Propriedade Intelectual”. No entanto, demais campos de atuação do Direito logicamente, interferem ou podem vir a interferirem na atuação do Sistema de Proteção da Propriedade Intelectual e ou em uma nova forma de proteção. 
O DIREITO E A PROPRIEDADE INTELECTUAL: CONSTITUCIONALIZAÇÃO, CAMPO DE ATUAÇÃO E

RESPONSABILIDADE A VIOLAÇÃO DO DIREITO.

E-ISSN 2316-8080

Passa-se a refletir em seguida sobre o sistema jurídico e a proteção à Propriedade Intelectual com ênfase as bases constitucionais desta.

\section{1 - As Bases Constitucionais da Propriedade Intelectual.}

Diante das pesquisas e estudos na área é possível perceber que, a existência de uma referência teórica e de uma estrutura institucional para amparar a observância e a efetividade dos direitos regulamentados à Propriedade Intelectual são reconhecidas e incentivam a inovação e a criatividade, contribuindo para o progresso socioeconômico, cultural, comercial e tecnológico, possuindo, no Brasil, fundamento principal na Constituição Federal de 1988 e em diversas Leis Ordinárias, Normas Infraconstitucionais , Tratados e Acordos Internacionais dos quais o país é signatário. No nível Infraconstitucional a questão é regulada através de um conjunto de normas, dentre elas a Lei 10.973/2004, conhecida como Lei da Inovação em que estabelece medidas de incentivo podendo ser classificadas segundo a natureza das ações que visa impulsionar; a Lei de Propriedade Industrial, Lei 9279/1996; Lei 8884/1994 do CADE (Conselho Administrativo de Defesa Econômica); Lei 12529/2011 que criou o SBDC (Sistema Brasileiro de Defesa da Concorrência), dentre outras tantas, leis especificas, decretos, resoluções.

\footnotetext{
Verifica-se, portanto, que a interpretação e aplicação do marco regulatório da inovação cientifica e tecnológica demanda do operador do Direito, além do conhecimento das regras jurídicas aplicáveis à matéria, a competência para recorrer à pauta de princípios jurídicos e daí extrair argumentos racionais e proporcionais dentro dos contornos da juridicidade, capazes de permitir a demonstração transparente da adequação e pertinência entre a decisão interpretativa adotada e as premissas do sistema jurídico especifico (BOCCHINO,2012,p.69).
}

Assim, o Sistema Normativo do Direito Brasileiro é integrado por princípios e regras jurídicas, sendo os princípios reconhecidos como valores que uma determinada sociedade, historicamente considera, elege-os como significativos e, por essa razão os vivencia, estando inseridos no arcabouço jurídico, encontrados como normas-principio na Constituição Federal de 1988, com previsão expressa e implícita. Quanto às regras jurídicas, estas, funcionam em geral, como instrumento de materialização dos princípios.

Os princípios do Direito cumprem dupla funcionalidade: 1- $\underline{\text { A Funcionalidade }}$ Teológica, com função finalística, como fundamento do sistema jurídico, indicando os 
princípios, do ponto de vista jurídico, os fins a serem socialmente alcançados; 2Funcionalidade Metodológica, em que em seu cumprimento de função metodológica, os princípios apontam o caminho interpretativo a percorrer, alinhando e atribuindo sentido às formulações estabelecidas nas regras e ao sistema como um todo.

A Lei Maior afirma a dignidade da pessoa humana como um dos fundamentos da República e, a liberdade, a justiça social e a solidariedade, como alguns dos objetivos fundamentais do Estado Brasileiro. Dessa forma, as questões que se revelam mais relevantes para a vida social encontram reflexo nos princípios jurídicos (AGU.vol2, p.67).

As Leis no Ordenamento Jurídico Brasileiro possuem uma organização a nível hierárquico que para melhor entendimento, ressalta-se neste contexto, a sua organização, observando no ilustrativo abaixo, a relação hierárquica existente entre as diferentes espécies normativas que integram o ordenamento jurídico brasileiro.

Cabe lembrar que o Instituto Propriedade Intelectual em seu Sistema de Proteção, confere primeiramente o amparo legal as leis nacionais, que neste caso possuem previsão na Constituição Federal/88, a seguir nas normas infraconstitucionais, que são posteriores a Constituição e nos Tratados e Acordos Internacionais dos quais o Brasil é signatário. Em segundo, a Organização Internacional de Propriedade Intelectual (OMPI). Percebese que a proteção à Propriedade Intelectual nasce da lei, e que segundo Barbosa (2002):

Há um dos mais interessantes efeitos da doutrina do market failure é evidenciar a natureza primária da intervenção do Estado na proteção da Propriedade Intelectual. Assim é que a intervenção é necessária, restringindo as forças livres da concorrência e criando restrições legais a tais forças, pois que a criação da Propriedade Intelectual é completa e exclusivamente uma elaboração da lei, que não resulta de qualquer direito, anterior a tal legislação. Mesmo após a criação das leis de propriedade intelectual, o que permanece fora do escopo especifico da proteção fica no res communis ominium - o domínio comum da humanidade (p.04).

Segundo a Constituição Federal de 1988, a concorrência se inaugura com uma declaração a favor da liberdade de iniciativa, inserindo entre os princípios da Ordem Econômica o princípio da liberdade de concorrência, em que para a iniciativa privada, o Estado não exercerá diretamente atividade econômica, a não ser que seja necessária intervenção, quanto à segurança nacional ou relevante interesse coletivo, em que ambos os casos sejam tratados conforme a lei. O dispositivo do Artigo 173 da Constituição Federal de 1988 fundamenta o tratamento constitucional ao investimento privado.

Regra constitucional também de extrema relevância é a que se lê no Art.174 da mesma Carta, de que o Estado, como agente normativo e regulador da atividade econômica, exercerá funções de fiscalização, incentivo e planejamento, as quais, para o setor privado, terão efeito meramente indicativo (Idem, 2002, p. 04). 
Ainda, confere nos incisos XXVII, XXVIII e XXIX do artigo $5^{\circ}$ da $\mathrm{CF} / 88$, a Propriedade Intelectual entre o rol das garantias fundamentais do homem, em um contexto de inviolabilidade da propriedade, como cláusula imodificável, sendo a sua interpretação , sistemática e finalística, destinando-se à todos os indivíduos, brasileiros ou estrangeiros residentes, ou não, que venham a se encontrar no território nacional, sem distinção de qualquer natureza. Já os direitos intelectuais de conteúdo essencialmente industrial, em relação ao contexto constitucional, são objetos de tutela própria e não se confundem com a regulação patrimonial de cunho econômico do direito de autor.

Entende-se, portanto que, o interesse tutelado em relação ao objeto de estudo Instituto da Propriedade Intelectual, no que concerne ao seu Sistema de Proteção é a necessidade social de favorecer a inovação nos conhecimentos e nas criações estéticas, conduzindo investimento privado a tais campos, com objetivo de obter o interesse coletivo, a lei institui uma restrição às liberdades públicas, favorecendo os interesses privados. Logo, uma vez realizado o objetivo do interesse público através da criação de condições de investimento privado, reequilibra-se o balanço. Quando a propriedade intelectual integra o patrimônio intangível das pessoas jurídicas de direito público, como as autarquias e as fundações públicas, ela é considerada um bem público e quando integram ao acervo de riqueza da instituição pública, destinadas à utilização pelos interessados, geralmente denominado setor produtivo ou empresarial privado, a oportunidade e forma de alienação estão subordinados à disciplina distinta do mesmo comércio realizado entre particulares.

Lembrando que poderá ocorrer colisão de dois ou mais direitos constitucionais igualmente valiosos, e que nestes casos, deverá então impor-se as regras da razoabilidade, ponderação ou balanceamento.

Segundo, Barbosa (2002), a razoabilidade entende-se:

(...) O que vem a ser a razoabilidade, que o STF e os doutos entendem como indispensável à aplicação das normas e ao procedimento administrativo? $\mathrm{O}$ razoável é, em primeiro lugar, o que decorre do senso normal de pessoas equilibradas e respeitosas das finalidades que presidiram a outorga da competência exercida. O razoável é também a adequação de meios a fins, de uma forma lógica e funcionalmente adequada. Com efeito, tal regra constitucional presume que a restrição consista no meio mais idôneo de se conseguir os seus fins com a menor restrição possível. Em terceiro lugar, razoabilidade é a regra de menor interferência no status quo, com vistas a assegurar a máxima segurança jurídica, e a mínima intervenção estatal no âmbito jurídico das pessoas privadas (p.09). 
Como a Propriedade Intelectual é regulamentada por Órgão Público FederalInstituto Nacional de Propriedade Industrial (INPI) é importante frisar o entendimento da posição dos órgãos públicos neste contexto.

Em relação aos órgãos públicos, segundo a Lei Federal n $n^{0}$ 9.784/99, referentes ao processo administrativo no âmbito da Administração Pública Federal, apresenta a concepção de órgão público como "a unidade de atuação integrante da estrutura da Administração Direta e da estrutura da Administração Indireta". Porém;

(...) órgãos públicos não se confundem com a pessoa pública que a integram. Correspondem a um conjunto de competências pertencentes à pessoa pública. Não existem por si, mas em razão de integrarem uma pessoa jurídica. $\mathrm{Na}$ Administração Direta Federal somente a União possui personalidade jurídica. Os Ministérios, por exemplo, órgãos da Administração Direta Federal, são centros de competência despersonalizados, cuja atuação é imputada à União. Deve-se atentar que a distribuição de competências em unidades despersonalizadas pode ocorrer tanto na Administração Direta como na Indireta (BOCCHINO, 2018, p.09).

Sendo que a organização da Administração Pública brasileira se apresenta em dois importantes instrumentos: 1-a descentralização e; 2-a desconcentração, em que a primeira, refere-se às competências que são transferidas para pessoas diferentes daquela que as detinha originalmente. Como por exemplo, às pessoas jurídicas que integram a administração indireta: autarquias, fundações públicas, empresas públicas e sociedades de economia mista e; a segunda, a desconcentração que consiste em uma distribuição de competências dentro da estrutura de uma mesma pessoa jurídica. Cada conjunto de competências assim reunidas, sendo cada complexo de atribuições organizado dentro da estrutura da pessoa jurídica considerado tecnicamente, um órgão, sendo, portanto, órgãos públicos, conjuntos de competências reunidos no interior de uma pessoa pública, em que se tem órgãos públicos na estrutura interna de cada uma das pessoas que compõem a nossa Federação - União, Estados, Distrito Federal e Municípios - e, também, no interior das entidades das respectivas administrações indiretas.

No entanto, mesmo sendo o Instituto Propriedade Intelectual apresentado por um sistema de proteção legal, ainda atualmente, em nosso país, existe atraso no que concerne às formas genéricas na competência para dirimir, controvérsias na área civil, os tipos penais existentes e a competência jurisdicional para exercer a persecução penal, dificultando assim, a tutela efetiva dos direitos assegurados à Propriedade Intelectual.

Em nosso país, a proteção à propriedade intelectual, por um lado, possui fundamento na Constituição e em diversas leis ordinárias, mas por outro, ainda necessita de maior efetividade, especialmente em virtude da pirataria e da 
prática de infrações civis e penais por meio da rede mundial de computadores. Mesmo com leis recentes, o Brasil está com atraso de aproximadamente 40 anos na forma de regulamentação da propriedade intelectual, em relação ao seu tratamento no Direito Internacional (CARDOSO, 2008, p.52).

Enquanto os organismos internacionais: Organização das Nações Unidas (ONU) e Organização Mundial do Comércio (OMC) conferem proteção ampla e uniforme, o Brasil ainda tenta se reorganizar a um custo financeiro dispendioso, em que editou diversos atos normativos sobre o tema, manteve ao mesmo tempo, órgãos já existentes criando atribuições para outros, descentralizando o controle e a fiscalização, através das leis especificas ao Sistema de Proteção à Propriedade Intelectual nas formas de proteção: da Propriedade Industrial; dos Cultivares; da Propriedade Intelectual de Programas de Computadores; dos Direitos Autorais, dos Medicamentos Genéricos, dos Organismos Geneticamente Modificados- Transgênicos; dos Semicondutores e Circuitos Integrados, dentre outros. Em consequência, percebe-se a criação de diversos órgãos, públicos ou privados, com atribuições especificas em cada um deles (ANVISA- Agência Nacional de Vigilância Sanitária; INPI; MAPA; CADE dentre outros), uma estrutura que pode vir a ser desnecessária onerosa e que dificulta a efetiva repressão às violações legais, segundo posição de doutrinadores, frente a atualidade em que se apresenta o Sistema de Proteção à Propriedade Intelectual e o que foi possível levantar, segundo a revisão literária realizada.

\footnotetext{
O desrespeito às normas e princípios relativos ao assunto produz em princípio, a responsabilidade civil de seu infrator. Além disso, essa violação pode também importar um ilícito penal, e seu autor sofrer a persecução penal por parte do Estado. Entre as diferenças existentes nas normas materiais e processuais dos Direitos civil e penal, destaca-se a das regras de competência, que causam ainda maiores dificuldades na repressão às lesões perpetradas contra os direitos da propriedade intelectual (CARDOSO, 2008, p.52).
}

O reconhecimento do direito à Propriedade Intelectual e seu sistema de proteção, assim, possuem proteção na legislação nacional e no Direito Internacional, com a finalidade de se efetivar a tutela jurisdicional dos direitos da Propriedade Intelectual através da criação de juízos especiais para dirimir questões relativas a tal instituto. Mesmo com os Tratados e Acordos vigentes não são suficientes para fazer valer o que se propõe, tendo mais concentração as principais negociações e acordos internacionais atualmente pela OMPI (Organização Mundial de Propriedade Intelectual e na OMC (Organização Mundial do Comércio). 
Existe com isso, também dificuldade na tutela desses direitos, não somente em virtude da quantidade de atos normativos e instituições existentes, mas também da diferença na repressão aos ilícitos civis e penais. Entretanto em regra nas ações cíveis, a competência é da Justiça Federal, as violações em relação aos direitos autorais é de competência para julgar a Justiça Estadual, sendo na maior parte dos casos a ação penal é privada, considerando que os direitos da Propriedade Intelectual são direitos privados, apesar de sua fiscalização, exercício do uso exclusivo e sua regulamentação depender, em regra, de atos do Poder Público.

Tais distinções criam empecilhos à proteção e à atuação uniforme quanto aos direitos da propriedade intelectual, causando insegurança jurídica e não conferindo a necessária tutela, dificultando também o efetivo desenvolvimento socioeconômico, cultural, comercial, tecnológico no país. Logo, é importante debater o modo pelo qual o tema é regulamentado no país, a fim de harmonizálo ao Direito Internacional e unificar a sua normatização e proteção, garantindo, dessa forma, o respeito aos direitos e o incentivo à produção intelectual no Brasil (CARDOSO,2008, p.56).

Assim, ao titular de Propriedade Intelectual, no âmbito civil, assegura-se o direito de ação para defender e reparar prejuízos que lhe forem causados em eventual violação do direito ou de concorrência desleal, independentemente, da ação criminal, o prejudicado pode intentar as ações cíveis cabíveis na forma do CPC-Código de Processo Civil.

Em se tratando do Direito de Propriedade Industrial, tendo em vista que o INPI é uma autarquia Federal, em regra a competência é da Justiça Federal para processar e julgar causas relativas à nulidade de registros ou patentes. Quando, o INPI, não for autor, deverá intervir no feito, sendo a competência da Justiça Federal.

No entanto, segundo Cardoso (2008), o Supremo Tribunal de Justiça, entende que a Justiça Estadual, possui competência para decidir sobre a nulidade da patente como questão prejudicial, produzindo efeitos inter partes.

Justifica-se o argumento, segundo o autor acima citado, de que o ato administrativo do INPI que concede o registro ou a patente não se confunde com o direito real sobre estes, que por sua vez são debatidos judicialmente, limitando a Administração Pública, a verificar se o postulante preenche ou não os requisitos legais necessários.

Segundo Neto (2018), ao contrário do que muitos defendem, em um primeiro momento é necessário frisar que, o bem tutelado é coletivo e não privado, derivando de Tratados Internacionais e Normas Constitucionais que o elevam a direito fundamental, embora parte de doutrinadores defenda o contrário, pois com o intuito do 
desenvolvimento cultural e tecnológico, o Estado garante aos criadores e inventores determinado monopólio na utilização onerosa e não onerosa de sua obra ou invento.

O Direito da Propriedade Intelectual aborda que, antes de regular as questões comerciais, contratuais e de competição desleal, trata de troca entre o criador e o Estado, trocando tecnologia/cultura pela exclusividade de exploração, ou pelo menos uma exclusividade temporária, na maioria dos casos.

O Estado não proíbe a concorrência empresarial salutar e sim estimula e incentiva a livre competição como forma de aprimoramento das atividades comerciais, industriais, tecnológicas e consequentemente o desenvolvimento econômico. O que o Estado reprime é a concorrência feita de forma ilícita, contrária às práticas honestas, éticas e leais, tendo fundamento na Constituição Federal de 1988 em seu artigo 173, § 4, “a lei reprimirá o abuso do poder econômico que vise à dominação de mercados, à eliminação da concorrência e ao aumento arbitrário de lucros" e a tal abuso temos a denominada concorrência desleal, podendo ser encontrada no artigo 10 bis da Convenção da União de Paris (CUP) de 1967, para a Proteção da Propriedade Industrial, em que:

\footnotetext{
1)- Os países da União obrigam-se a assegurar aos nacionais dos países da União proteção efetiva contra a concorrência desleal;2)- Constitui ato de concorrência desleal qualquer ato de concorrência contrário aos usos honestos em matéria industrial ou comercial; 3)- Deverão proibir-se especialmente: $1^{\circ}$ Todos os atos suscetíveis de, por qualquer meio, estabelecer confusão com o estabelecimento, os produtos ou a atividade industrial ou comercial de um concorrente; $2^{\circ}$ As falsas afirmações no exercício do comércio, suscetíveis de desacreditar o estabelecimento, os produtos ou a atividade industrial ou comercial de um concorrente; $3^{\circ}$ As indicações ou afirmações cuja utilização no exercício do comércio seja suscetível de induzir o público em erro sobre a natureza, modo de fabrico, características, possibilidades de utilização ou quantidade das mercadorias.
}

\section{2- Quanto aos princípios de Direito Administrativo aplicados ao Instituto}

\section{Propriedade Intelectual.}

A de se considerar os princípios constitucionais da Administração Pública como foco e especificamente a Propriedade Industrial como ramo do Direito Administrativo, sendo necessário a realização do enlace prático entre ambas, justificando-se pelo fato do Instituto Nacional da Propriedade Intelectual (INPI) ser autarquia Federal e, de acordo com a Lei $n^{\circ} 9.279$ de 1996, a Lei $n^{\circ} 9.609$, de 1998 e a Lei n ${ }^{\circ} 11.484$, de 2007, ser responsável pelos registros de Marcas, de Desenho Industrial, de Indicações Geográficas, 
de Topografia de Circuitos Integrados e de Programas de Computadores, Concessão de Patentes, Averbação de Contratos de Transferência de Tecnologia e de Franquia Empresarial.

A Constituição Federal de 1988 em seu artigo 37 aponta expressamente os princípios da Administração Pública, sendo eles: 1- O Princípio da Legalidade; 2Princípio da Impessoalidade; 3- Princípio da Moralidade; 4- Princípio da Publicidade e 5- Princípio da Eficiência.

Os princípios são os pilares que sustentam a ordem jurídica, possuindo força cogente e servindo de inspiração para elaboração e execução das normas, respectivamente. Neste sentido, eventual ofensa a um princípio é muito mais danosa do que um descumprimento da norma, posto que afrontar um princípio implica desrespeitar a ordem jurídica em sua gênese (NOGUEIRA, 2009, p.57).

Destacam-se as concepções de cada princípio apontado acima para melhor compreensão segundo Di Pietro (2006):

A-Princípio da Legalidade: principio pelo qual a Administração Pública somente pode fazer o que a lei determinar ou permitir. Na prática, é admitir que a Administração Pública, não poderá realizar coisa alguma sem que haja uma lei prévia ditando que está autorizada ou tem a obrigação de fazê-la. Ainda, cabe ressaltar a diferença entre o princípio da legalidade para a Administração e o princípio da legalidade para o particular. Aquele está revisto no artigo 37, caput, da CF, e este, no artigo $5^{\circ}$, inciso II, da mesma constituição: "ninguém será obrigado a fazer ou deixar de fazer alguma coisa senão em virtude de lei".

B-Princípio da Impessoalidade: princípio pelo qual se impõe tratamento igualitário às pessoas, respeito à finalidade e também a ideia de que os atos dos agentes públicos devem ser imputados diretamente à Administração Pública e não a pessoa do agente.

C-Princípio da Moralidade Administrativa: preceitua a obediência à ética da Administração, consistente no conjunto de preceitos da moral administrativa, como o dever de honestidade, lealdade, boa-fé e probidade e que segundo a Constituição Federal em seu art. $5^{\circ}$, inciso LXXIII, refere-se a moralidade administrativa estando presente no interior da administração e não no bojo da sociedade como um todo. No entanto, cabe ressaltar que o artigo $11 \mathrm{da} \mathrm{CF}$, incorpora preceitos morais a serem seguidos, como: honestidade e a lealdade às instituições. O que caberia também a Propriedade Intelectual.

D- Princípio da Publicidade- principio pelo qual é imposto a ampla_divulgação dos atos oficiais, para conhecimento público e início dos efeitos externos, revelando dois 
O DIREITO E A PROPRIEDADE INTELECTUAL: CONSTITUCIONALIZAÇÃO, CAMPO DE ATUAÇÃO E

RESPONSABILIDADE A VIOLAÇÃO DO DIREITO.

E-ISSN 2316-8080

sentidos importantes:1- garantir que todos tenham acesso, conhecimento dos atos da Administração Pública e; 2- garantir que os atos oficiais possuam efeitos externos após a sua publicação, ressalvadas aquelas informações cujo sigilo seja imprescindível à segurança da sociedade e do Estado- Lei 12527/2011 regula o acesso à informação prevista no inciso XXXIII, sendo aplicada à todos entes federativos.

E- Princípio da Eficiência: principio pelo qual se impõe o dever de a Administração Pública atender de forma satisfatória às necessidades dos administrados, bem como de o administrador público fazer o melhor, como profissional, diante dos meios de que dispõe.

$\mathrm{Na}$ esfera infraconstitucional, os princípios administrativos possuem previsão na Lei ${ }^{\circ}$ 9.784, de 29 de janeiro de 1999, em seu artigo $2^{\circ}$, em que toda ação de seus agentes deve demonstrar em seus atos, de modo inequívoco, a sua pertinência principiológica e os princípios jurídicos em que se materializam.

\section{3- Reponsabilidade: Civil, Penal e Administrativa.}

Tenta-se aproximar a ideia do que venha a ser o termo "Responsabilidade" e o nexo com o Instituto de Propriedade Intelectual no que confere aos campos: Civil, Penal e Administrativo.

Segundo Dias (1997), toda manifestação referente à atividade humana, traz consigo a problemática da responsabilidade, sendo tal fato questão problema para fixar a sua concepção, pois a responsabilidade não é fenômeno exclusivo da vida jurídica, antes se conecta a todos os domínios da vida social.

Para melhor entendimento, faz-se recorte na ideia do interesse, quando se fala de responsabilidade referente à questão, de violação da norma ou obrigação diante da qual se encontra o agente, em que tendo violado uma norma qualquer, se vê exposto às consequências desagradáveis decorrentes dessa violação, de que por sua vez, são traduzidas em medidas das quais a autoridade encarregada de velar pela observação do preceito deve tomar providências. Responsabilidade então exprime a ideia de restauração de equilíbrio, de contraprestação, e de reparação de dano. Sendo múltiplas as atividades humanas, inúmeras serão também as espécies de responsabilidade. 
Tem-se destaque também neste contexto, para a responsabilidade jurídica e responsabilidade moral, podendo ocorrer separadas ou concomitantemente, dependendo do fato que configure a infração.

O campo moral é mais amplo do que a do direito, pois só se cogita a responsabilidade jurídica quando há prejuízo. Esta só se revela quando ocorre infração da norma jurídica que acarrete dano ao indivíduo ou à coletividade. Neste caso, o autor da lesão será obrigado a recompor o direito atingido, reparando em espécie ou em pecúnia o mal causado e que segundo, Gonçalves (2014, p.20), já, “a responsabilidade moral é confinada à consciência, e não se exterioriza socialmente, não tem repercussão na ordem jurídica. Pressupõe, porém o livre-arbitrio e a consciência da obrigação” em que pese, quanto a distinção entre obrigação e responsabilidade. A primeira é sempre um dever jurídico originário e a segunda, um dever jurídico sucessivo consequente à violação da primeira, ou seja, caso não cumpra a obrigação, deixar de prestar os serviços, violará o dever jurídico originário, surgindo à responsabilidade, no dever de compor o prejuízo causado pelo não cumprimento da obrigação.

\footnotetext{
Em síntese, em toda obrigação há um dever jurídico originário, enquanto na responsabilidade há um dever jurídico sucessivo. E, sendo a responsabilidade uma espécie de sombra da obrigação, sempre que quisermos saber quem é o responsável teremos de observar a quem a lei imputou a obrigação ou o dever originário (GONÇALVES, 2014, p.21).
}

Quanto à responsabilidade civil, pode ser compreendida como um conjunto de medidas, que são impostas em decorrência de um dano para repará-lo, com as finalidades da satisfação à vítima; o conteúdo dessa reparação sendo reparatório ou de compensação; reequilíbrio na sociedade ou nas relações jurídicas da lesão, ou seja, do dano (moral ou material). A reparação ou indenização poderá ser exigida por conta de um ato ilícito, ou por conta de um risco, potencialidade para a produção de dano. Logo, na responsabilidade civil, o interesse lesado é o privado, sendo o prejudicado com direito de pleitear ou não a reparação. É de natureza patrimonial, pois é o patrimônio do devedor que responderá por suas obrigações.

A responsabilidade civil se subdivide em extracontratual e contratual. A responsabilidade extracontratual refere-se à responsabilidade que não deriva de contrato, em que aquele que causa dano a outrem, por culpa em sentido estrito ou dolo, fica obrigado a repará-lo. Em regra é subjetiva, decorrente de ato ilícito, mas poderá ser objetiva em alguns casos. A culpa não é presumida, sendo necessário ser provada pelo interessado. Já a responsabilidade contratual é oriunda de um contrato, referindo-se ao 
O DIREITO E A PROPRIEDADE INTELECTUAL: CONSTITUCIONALIZAÇÃO, CAMPO DE ATUAÇÃO E

RESPONSABILIDADE A VIOLAÇÃO DO DIREITO.

E-ISSN 2316-8080

descumprimento de uma obrigação contratual, também em regra pode ser subjetiva, como objetiva, em que a culpa do devedor é presumida, devendo este comprovar a inexistência desta.

Quanto ao dano material, moral e estético com perspectivas à Propriedade Intelectual e o seu Sistema de Proteção, verifica-se a possibilidade de incidência em todas as formas em que a Propriedade Intelectual se configura.

Em relação ao dano- É lesão a um direito, interesse, ou bem jurídica. Tal lesão pode ser de âmbito material, moral e/ou estético, podendo um mesmo comportamento ocasionar nas três lesões, em que:

1-Dano Material-é o dano que afeta tão somente o patrimônio do ofendido, ao passo que moral é o que ofende o devedor como ser humano, sem lhe atingir o patrimônio.

2-Dano Moral- é a ofensa ao foro íntimo da pessoa, em que os Direitos de Personalidade são aqueles inerentes à dignidade da pessoa, devendo ser comprovado, apesar de que é presumido em algumas situações.

3-Dano Estético- considera-se o agravo à imagem física da pessoa, enquanto que o dano moral não necessariamente. No entanto, segundo a Súmula 387, é possível a cumulação das indenizações do dano estético e moral.

Já a responsabilidade penal, esta é pessoal e intransferível em que responde o réu com a privação de sua liberdade, cujo agente infringe uma norma jurídica, exigindo-se a investigação da culpabilidade deste ou o estabelecimento da anti-socialidade do seu procedimento.

A diferença entre responsabilidade civil e responsabilidade penal está na norma jurídica violada. Se ela atingir a um interesse de toda a sociedade, a responsabilidade será penal ou criminal. No entanto, se atingir apenas o âmbito privado, será tão somente civil. Ou seja, na responsabilidade penal, o agente infringe uma norma de direito público, sendo o interesse lesado, o da sociedade, enquanto a responsabilidade civil, o interesse lesado é o privado, de modo que o prejudicado poderá ou não pleitear a sua reparação.

Em relação ao processo judicial, a ação penal pode suspender por um ano o processo civil, mas dependendo do caso concreto, pode-se suspender a ação civil por um prazo maior que este. Não sendo uma suspensão obrigatória, mas conveniente, pois evita a prolação de decisões conflitantes. Logo após o decurso do prazo da suspensão, o 
processo civil pode voltar a tramitar, mas o ideal é aguardar o trânsito em julgado da ação penal.

Quanto à responsabilidade administrativa, para melhor entendimento, resgata-se um dos princípios que representa uma das principais garantias de respeito aos direitos individuais, o Princípio da Legalidade, em que a Administração Pública, somente deve fazer aquilo que na lei constar, diferentemente das relações envolvendo particulares, em que o que não está previsto ou proibido por lei é permitido.

Cabe assim, ao administrador público, na gestão da Propriedade Intelectual, a aplicação da legislação pertinente, não podendo, por simples ato administrativo e à revelia da lei, conceder ou restringir direito ou vantagem de qualquer espécie da que não esteja prevista em lei. Dessa forma, compete aos órgãos públicos da Administração Pública promover políticas de desenvolvimento e fortalecimento da Ciência e Tecnologia, estabelecendo normas próprias de proteção referentes aos seus ativos intangíveis. Respeita-se também, além dos preceitos constitucionais da Administração, a legislação que afeta a matéria e os tramites do Processo Administrativo que possui previsão na Lei $n^{\circ} 9.784$ de 1999.

Para Bocchino (2018):

Observa-se que o sentido do princípio da legalidade não se exaure com o significado de habilitação legal, mas também no sentido de ser vedado à Administração editar atos ou tomar medidas contrárias às normas do ordenamento. Em verdade, se por um lado o princípio da legalidade representa uma espécie de limite para a atuação do poder público, por outro, visa à proteção do administrado em relação ao abuso deste poder (P.26).

Importa-se observar também, em relação ao Princípio da Legalidade, a relevância dos contratos, convênios e acordos de parcerias e as funções que compete ao INPI, em relação a Propriedade Intelectual e Instituições Públicas, que ao se constituir em fontes de direitos e obrigações, se imbui de força de lei entre as partes, devendo o administrador público estar atento as responsabilidades.

Nesse sentido o Princípio da Legalidade resume-se na submissão em relação ao poder público aos mandamentos da lei e as atividades da Administração Pública a submeterem-se e limitarem-se a determinação da legislação, em que a atuação do poder público sem o encalço normativo acarreta a ilegalidade do ato, estando sujeito à nulidade.

Em se tratando de violação, tanto a pessoa física como a pessoa jurídica podem ser titulares de direitos patrimoniais e morais, sobre as diversas formas em que o Sistema de Propriedade Intelectual atua, devendo ser coibidos de forma célere, contundente e efetiva, todo tipo de violação que fere os preceitos estabelecidos. Logo: 


\begin{abstract}
Os Direitos de Propriedade Intelectual são tutelados nos âmbitos administrativo, penal e civil. Quem desrespeitar esses direitos poderá ser responsabilizado nessas três esferas, de modo simultâneo, isolado ou sucessivo. Portanto, além de ter o dever de indenizar os danos materiais e, eventualmente, morais causados ao titular dos Direitos de Propriedade Intelectual, o infrator também poderá responder a um processo com a legislação especifica de cada forma de proteção (BAGNATO, MURAKAWA e SOUZA, 2016, p.06).
\end{abstract}

Somente com a atuação efetiva e constante do Poder Judiciário e do INPI é que a troca entre o criador e o Estado tornar-se-á equilibrada e estimulará o privado a disponibilizar o seu conhecimento ao Estado, bem como as Universidades para o atendimento aos problemas da sociedade e das políticas públicas de apoio ao desenvolvimento tecnológico em relação à aplicação e comercialização do conhecimento gerado pelas pesquisas acadêmicas.

Lembrando que o registro de uma patente exige a publicação da tecnologia e em se tratando de invento original e com aplicação industrial, o produto do conhecimento ficará protegido no país de origem ou no exterior por um prazo determinado, em média de 20 anos, durante o qual o inventor poderá explorá-lo comercialmente ou licenciá-lo em troca de pagamento de royalties, antes que caia em domínio público.

Assim, espera-se que, com a pesquisa apresentada neste capítulo, tenha de certa forma alcançado o objetivo proposto: "Relacionar os direitos de Propriedade Intelectual nos âmbitos do Direito em relação à Constituição Federal, a responsabilidade e violação dos direitos: Civil, Penal e Administrativa ,bem como a atuação de outros campos do Direito em relação ao Instituto Propriedade Intelectual, através da revisão literária em diversas fontes bibliográficas".

\title{
Referências Bibliográficas:
}

BARBOSA, Denis Borges. Bases Constitucionais da Propriedade Intelectual. Disponível em: http://www.nbb.com.br/pub/propriedade13.pdf . Acesso em 18 de junho de 2018.

BOBBIO, Norberto. A Era dos Direitos. Trad. Carlos Nelson Coutinho. Rio de Janeiro, Campus, $1992 . \quad$ Disponível em: https://direitoufma2010.files.wordpress.com/2010/05/norberto-bobbio-a-era-dosdireitos.pdf. Acesso em: 19 de julho de 2018 
BOCCHINO, Lesleia de Oliveira ... [et al]. Propriedade Intelectual: conceito e procedimentos. Publicação da Escola da AGU. Brasília, nº 14, Vol. 2. Brasília: Advocacia Geral da União, 2012. Disponível em: www.agu.gov.br/page/download/index/id/10512183. Acesso em julho de 2018

BOCCHINO, Lesleia de Oliveira ... [et al]. Propriedade Intelectual: conceito e procedimentos. Vol. 06 Brasília: Advocacia Geral da União, 2010. Disponível em: www.agu.gov.br/page/download/index/id/10512183. Acesso em julho de 2018.

BOCCHINO, Lesleia de Oliveira ... [et al]. Princípios de Direito Administrativo aplicado à Propriedade Intelectual. Disponível em: https://seer.agu.gov.br/index.php/EAGU/article/viewFile/1668/1350 . Acesso em 29 de setembro de 2018 .

CAMINHA, Marco Aurélio Lustosa. O conceito de Direito. Universidade Federal de Goiás- Faculdade de Direito. Disponível em:https://www.direito.ufg.br/n/694-artigo-oconceito-de-direito. Acesso em 10 de setembro de 2018.

CARDOSO, Oscar Valente. A competência da Justiça Federal na Tutela dos Direitos da Propriedade Intelectual. Revista CEJ, Brasília, ano XII, p.51-56, out/dez, 2008. Disponível em: www.corteidh.oi.cr/tables/R22944pdf . Acesso em: 09 de setembro de 2018.

CARVAlHO, Thiago Moreira; THOMÉ, Karin Marini. A função social do direito de propriedade intelectual brasileiro segundo uma perspectiva sociológica econômica. Revista Direito em Ação, Brasília, V.14, n 1, p.103-125, jan./jun. 2015.

DI PIETRO, Maria Sylvia Zanella. Direito Administrativo. 19 ed. São Paulo: Atlas, 2006.

DIAS, José de Aguiar. Da responsabilidade Civil I. Editora: Revista Forense, 1997, Rio de Janeiro.

GONÇALVES, Carlos Roberto. Direito das Coisas. Coleção Sinopses Jurídicas, V.03, 17. ed-São Paulo: Saraiva, 2016.

GONÇALVES, Carlos Roberto. Direto das Obrigações: Parte Especial- Contratos. Coleção Sinopses Jurídicas, 06, Tomo I. 17. ed. São Paulo: Saraiva, 2015.

GONÇALVES, Carlos Roberto. Direito Civil Brasileiro: Responsabilidade Civil. 9. EdSão Paulo: Saraiva, 2014.

INSTITUTO NACIONAL DE PROPRIEDADE INDUSTRIAL- INPI. Propriedade Intelectual. Disponível em: http://www.inpi.gov.br/ .Acesso em: 22 de junho de 2018.

LIMA, José Erigutemberg Meneses. Afinal o que é Direito? Disponível em: https://guiteri.jusbrasil.com.br/artigos/152713024/afinal 0 que e direito. Acesso em: 10 de setembro de 2018. 
O DIREITO E A PROPRIEDADE INTELECTUAL: CONSTITUCIONALIZAÇÃO, CAMPO DE ATUAÇÃO E RESPONSABILIDADE A VIOLAÇÃO DO DIREITO.

E-ISSN 2316-8080

LIMA, Humberto Alves de Vasconcelos. Propriedade Intelectual no século XXI: Em busca de um novo conceito e substrato teórico. Revista da Faculdade de Direito- UFPR, Curitiba, no 56, p. 157-175, 2012. Disponível em: . Acesso em julho de 2018.

PLANALTO DO GOVERNO FEDERAL. Lei de Propriedade Industrial, $\mathbf{n}^{\mathbf{0}}$ 9.279/96: ARTIGOS: $\quad 5^{\circ}, \quad 10,11, \quad 13, \quad 14,42$ E 108 . Disponível em: http://www.planalto.gov.br/ccivil_03/Leis/L9279.htm. Acesso em: 13 de junho de 2018.

REALE, Miguel. Filosofia do Direito. 18. Ed. São Paulo: Saraiva 1998.

VECCHIO, Giorgio Del. Lições de Filosofia do Direito. [Tradução de Antônio José Brandão]. 8 ed. Coimbra: Sucessor, 2016. 